\title{
Patient safety incidents reported by relatives of hospitalized children
}

\author{
Incidentes de segurança com crianças hospitalizadas reportados por seus familiares \\ Incidentes de seguridad del paciente reportados por familiares de niños hospitalizados
}

\author{
Letícia Maria Hoffmanna \\ Fernanda Araujo Rodrigues $^{b}$ \\ Cecilia Biasibettia \\ Merianny de Avila Peres ${ }^{a}$ \\ Alessandra Vaccaria \\ Wiliam Wegner ${ }^{\mathrm{a}}$
}

\section{How to cite this article:}

Hoffmann LM, Rodrigues FA, Biasibetti C Peres MA, Vaccari A, Wegner W. Patient safety incidents reported by relatives of hospitalized children. Rev Gaúcha Enferm. 2020;41(esp):e20190172. doi: https://doi.org/10.1590/19831447.2020.20190172 a Universidade Federal do Rio Grande do Sul (UFRGS), Escola de Enfermagem. Porto Alegre, Rio Grande do Sul, Brasil.

• Secretaria Estadual de Saúde do Rio Grande do Sul. Porto Alegre, Rio Grande do Sul, Brasil.

\section{ABSTRACT}

Objective: To know the main safety incidents reported by relatives of patients hospitalized in pediatric units.

Methods: This is a qualitative research with exploratory-descriptive design. Data were collected between April 2016 and December 2017, in three hospitals in Porto Alegre/RS. A total of 91 semi-structured interviews were conducted with relatives of pediatric patients hospitalized in emergencies, infirmaries, and intensive care centers. The statements were transcribed in full and submitted to a thematic content analysis.

Results: The category Identification of safety incidents by relatives of hospitalized pediatric patients was formulated. Eight subtopics emerged: drug therapy, hand and environment hygiene, diet therapy, risk of falls, communication, patient identification, care processes/procedures and access to the institution.

Conclusions: The family identified safety incidents in various stages of care for hospitalized children. It is necessary to think about strategies that integrate the family in the care of children, to minimize risks and complications resulting from care.

Keywords: Patient safety. Pediatrics. Child, hospitalized. Caregivers. Family.

\section{RESUM0}

Objetivo: Conhecer os principais incidentes de segurança reportados por familiares de pacientes internados em unidades pediátricas. Métodos: Pesquisa de abordagem qualitativa com delineamento exploratório-descritivo. Os dados foram coletados entre abril/2016 e dezembro/2017, em três hospitais de Porto Alegre/RS. Realizaram-se 91 entrevistas semiestruturadas com familiares de pacientes pediátricos hospitalizados em emergências, enfermarias e centros de terapia intensiva. Os depoimentos foram transcritos na íntegra e submetidos à análise de conteúdo temática.

Resultados: Formulou-se a categoria Identificação de incidentes de segurança por familiares de pacientes pediátricos hospitalizados. Emergiram oito subtemas: terapia medicamentosa, higienização de mãos e ambiente, dietoterapia, risco de quedas, comunicação, identificação do paciente, processos/procedimentos assistenciais e acesso à instituição.

Conclusões: Os familiares identificaram incidentes de segurança em variadas etapas de cuidado à criança hospitalizada. Faz-se necessário pensar em estratégias de integração dos familiares no cuidado à criança para minimizar os riscos e incidentes relacionados ao cuidado.

Palavras-Chaves: Segurança do paciente. Pediatria. Criança hospitalizada. Cuidadores. Familiares.

\section{RESUMEN}

Objetivo: Conocer los principales incidentes de seguridad reportados por familiares de pacientes internados en unidades pediátricas. Métodos: Investigación de abordaje cualitativa con delineamiento exploratorio-descriptivo. Los datos fueron recolectados entre abril/2016 y diciembre/2017, en tres hospitales de Porto Alegre/RS. Se realizaron 91 entrevistas semiestructuradas con familiares de pacientes pediátricos hospitalizados en emergencias, enfermerías y centros de terapia intensiva. Los testimonios fueron transcritos en su totalidad y sometidos al análisis de contenido temático.

Resultados: Se formuló la categoría Identificación de incidentes de seguridad por familiares de pacientes pediátricos hospitalizados. Surgieron ocho subtemas: terapia con medicamentos, higiene de las manos y ambiente, dietoterapia, riesgo de caídas, comunicación, identificación del paciente, procesos/procedimientos asistenciales y acceso a institución.

Conclusiones: los familiares identificaron incidentes de seguridad en variadas etapas de cuidado al niño hospitalizado. Se hace necesario pensar en estrategias de integración de los familiares en el cuidado al niño, revirtiendo ese panorama inseguro de asistencia. Palabras clave: Seguridad del paciente. Pediatría. Niño hospitalizado. Cuidadores. Familia. 


\section{口INTRODUCTION}

Providing care for hospitalized children and adolescents involves procedures and techniques that expose them to risks. Adverse events are considered more likely to occur in pediatric assistance than in adults, besides having a higher potential to lead to more severe outcomes due to the particularities of development, anatomy and physiological systems of this age group.

According to the World Health Organization (WHO), patient safety is related to reducing the risk of unnecessary health-related harm to an acceptable minimum. Incidents are events that could result or resulted in unnecessary harm to the patient. When an incident does not affect the patient, it is usual to call the situation a near miss. When it affects the patient but causes no harm, it is called a harmless incident. The incident that results in harm to the patient is called harmful incident or adverse event ${ }^{(1)}$.

A study that analyzed adverse events that resulted in death at a national level indicated the occurrence of 48 deaths in the age group from under 28-day-old neonates to adolescents up to 17 years of age, in the period of two years ${ }^{(2)}$. Another study identified an occurrence of 34 reported incidents in pediatric clinic and neonatal intensive care units during approximately 45 days of study ${ }^{(3)}$.

Pediatric hospitalization is permeated by particular characteristics, such as the participation of full-time caregivers and the triggering of negative feelings in the caregiver and the child, such as fear and anguish, which alter the care to be provided by the health professionals. For the child, the situation can also be traumatic and risky due to the care procedures ${ }^{(4)}$, which force the companion to assume a crucial role together with the professionals, as agents promoting patient safety.

A study with patient relatives and their relationship with patient safety highlighted that caregiver perceptions of patient safety fall short in relation to the empirical knowledge of protection and paternal duties. With proper professional guidance, the companions receive the necessary knowledge to adopt behaviors that are adequate to a culture of patient safety. The caregivers show interest and availability to be oriented and to participate in childcare in a protective way, so that incidents do not affect the patient ${ }^{(5)}$.

This research is justified by the importance of further studies on this subject. The field of patient safety lacks researches with high reliability, that involve the culture of safety, open communication, and early detection of patient deterioration and sepsis in the context of pediatrics. An international study also addressed as a priority the investigation of errors in diagnostics, medication safety, and outpatient safety ${ }^{(6)}$.
Despite its recognized importance, there are still few studies investigating the identification of incidents in the perception of the patient, family member or caregiver. Thus, the question that guided this research was: how are safety incidents with hospitalized children perceived and reported by their relatives? The aim of this study was getting to know the main safety incidents reported by relatives of patients admitted to pediatric units.

This study was developed by the Group of Studies and Research in Nursing, Education and Technologies (GEPEE$T e c)$, which has been contributing to the production of knowledge in health and nursing for almost 10 years and is linked to the story of success of the 68 years of the School of Nursing and 20 years of the Graduation Nursing Program of the Universidade Federal do Rio Grande do Sul.

\section{METHOD}

This is a qualitative study with exploratory-descriptive design ${ }^{(7)}$. It is part of a central project entitled "Patient Safety in Hospital Child Care Services in the City of Porto Alegre / RS". Data were collected from April 2016 to December 2017, in three large hospitals in Porto Alegre / RS, with pediatric inpatient units, pediatric intensive care unit (PICU) and pediatric emergency unit, that attend users of the Unified Health System (SUS). The hospitals, together, are responsible for most of the healthcare offered to children with chronic diseases, cancer treatment, and highly complex care. Together they add up to more than 500 pediatric and neonatal hospitalization beds and are statewide referral centers for childcare.

The study interviewed 91 family members of pediatric patients admitted to wards (clinical and surgical units), intensive care centers, and pediatric emergencies sectors. Prior to data collection, the minimum number of six interviews per inpatient unit was stipulated; However, this number changed as interviews were conducted, since the empirical and theoretical saturation criteria was applied ${ }^{(7)}$. Therefore, there were 56 interviews in inpatient units, 17 in PICU, and 18 in emergencies sectors. Were included cases in which the relative was 18 years old or older, and the child was hospitalized for at least seven days in the ward or PICU, or six hours in the emergency room. Family members who were not the child's legal caregivers were excluded. This information was collected through patient records and/or directly with the professionals. The participants were chosen intentionally and the invitation to participate in the study was made at the patient's bedside.

Semi-structured interviews were performed and recorded in a digital device. Data collection was conducted by 
undergraduates who received scholarships and were trained for this purpose. The interview script addressed issues that prompted the caregiver to reflect on their knowledge about the issue, whether they had already identified failures, errors or risks in care, actions that affect patient safety, their role as a family member and caregiver, whether the family increases the safety of hospitalized children, and the essential factors to promote patient safety when admitted to a health service.

Initially, the interviews were transcribed in full and typed in Microsoft Word 2010 software, to a total of approximately 329 pages of empirical material. The participants statements were identified by the letter I, when performed in an inpatient unit; $U$, when performed in PICU, and $E$, when performed in the emergency services, and were preceded by a number according to the order of their realization. Subsequently, the material was organized using the QSR NVivo software version 11.0 and submitted to the thematic content analysis proposed by Minayo. The content analysis was made up by the Pre-analysis stage, which consists of an exhaustive reading of the material, organization of the material, formulation and reformulation of the study objectives; the exploration of the material, organizing the data collected into categories according to meaningful words or expressions; and finally, the treatment of the results obtained and their interpretation ${ }^{(7)}$.

Family members who participated in the study signed the Informed Consent Form. The study followed the norms of Resolution 466/12 of the National Health Council. The research was approved by the Research Ethics Committees from the proposing institution, under protocol No. 1.072.189 and the three co-participating institutions, under approval numbers 1.221.489, 1.383.292 and 1.175.995.

\section{口 RESULTS}

The results from the relatives statements were organized into a main category: Identification of safety incidents by relatives of hospitalized pediatric patients; with its subcategories: incidents in drug therapy, hand and environment hygiene, patient diet therapy, risk of patient falls, ineffective communication among those involved in child care, patient identification, care processes / procedures and safety in accessing the health institution; this study is a part of a larger study.

\section{Identification of safety incidents by relatives of hospitalized pediatric patients}

The statements in all sectors considered in the study were similar, which allowed the creation of major thematic axes according to the incidents reported by the companions in the inpatient units, $\mathrm{PICU}$, and pediatric emergencies rooms.

\section{Drug therapy}

The incidents occurred during various care processes, including medication. Relatives recognized drug related incidents, regarding delays in administration, miscommunication regarding therapy, incorrect dosage and infusion times, discontinuation of the wrong medication, lack of allergy bracelets, and near misses intercepted by the relative.

[...] she was going to give nebulization to my son, but he had already done it, then I told her [...] (I 1)

[...] because there are pills that must be taken one hour before food or one hour after [...] (I 30)

Once a chemotherapy that was to be infused in three hours, was infused in 55 minutes. And again, the programming was also done totally wrong, it was to infuse $318 \mathrm{~m} /$ in one hour and she set to infuse $26 \mathrm{ml}$ in one hour [...] (I 36)

[...] he is not wearing a bracelet for those with allergies, and he has an allergy [...] (I 47)

In this case, this medicine, how long it will be. Now they do it for a length of time, later for a different one, and then they come to correct. Then, I saw that they were really wrong [...] (U 10)

\section{Hand and environment hygiene}

Incidents related to hand hygiene and care in the dissemination of infectious diseases were present in the reports. Family members identified incorrect or even lacking hand hygiene at essential moments of care, and sometimes they were not performed by the children's own relatives. Errors were mentioned in the use of Personal Protective Equipment (PPE) in isolated patients and in the professional guidance regarding the use of these materials. The environment and 
children hygiene were also considered an important aspect in the quality of care and seen as fragile at times.

Because I see a lot of people coming in, both doctors, nurses, and technicians. They enter there, often touch a child, and even if they do not touch, they leave and go straight into our room [...] (1 51)

[...] I see that many people, father and mother, do not wash their hands very often when entering [...] (U 17)

Because, to start, they don't use the mask in the emergency room. I already told them to put the mask on him because I know he can't have these types of contact, right [...] (I 36)

[...] when the bath goes from one child to another, sometimes, they do not clean the place very well ... Don't use alcohol (in the sink where the baths are held) just wash with a cloth... very quickly [...] (I 50)

What I see, like, here... that I don't know where I read it, that there is ... I don't know if it's every day or week that you have to put alcohol in the crib. And this I see that almost nobody [...] / don't know if it would be part of this procedure ... but maybe clean the shelf. Because I spent a month in ICU I didn't see anyone cleaning it over, you know? (U 17)

\section{Diet therapy}

The diet therapy of hospitalized children presented incidents in its distribution process, delayed delivery of certain diets and in the release of NPO, food temperature, infusion of enteral diets, adaptation of hospital foods to the child's preferences, dosage and omission in nutritional therapy:

It happened when we managed to go to the inpatient floor and he has a Nasogastric tube, and with the lack of food he got very nervous and I asked them to take the tube. So, he was days without food [...] but there were two doctors [...] they denied me the NPT [...] He presented hypoglycemia, less than 20, and came to a convulsion for 8 minutes [...] So that was negligence to me $[. .].(\cup 7)$

[...] since she is used to eating a banana, an apple, having a yogurt [...] like here, until now nobody helped me to solve the situation [...] they don't care, nobody has solved this yet [...] Then they put in her medical record "she refused the breast, she refused the breast" [...] (E 2)

It happens to ask one thing and something else comes. Like she hates apple and it al ways comes, then I have to go there and replace it. (E 8)
Once, he was receiving a diet and they increased the diet. And it came with the extra diet and the prescription said it should be less. And they threw away what they didn't used, and then the prescription with the extra diet came [...] (U 17)

[...] Sometimes the workers who bring the food bring it wrong [...] So, sometimes, there is a cold bottle prescribed, but a hot one comes [...] (I 14)

[...] He was very hungry [...] then the nurse got him a snack. This morning when it was breakfast time, because the nurse had not communicated the kitchen that he was liberated [...] (I 37)

[...] the professional did not install the diet in the tube [...] she installed it but she did not connect the tip of the diet to it, did not remove the tube from the bag and put it on, and left it there on the bed. (I 57)

\section{Risk of falls}

As for the falls, there was a report of a fall by a companion and the mention by other participants of the risk of falls due to the absence of safer beds suitable for the size of children and unsafe practices by professionals.

He fell out of his crib, look at the grid, how it is [...] my identification fell and when I went to get it he turned over in the grid and hit his head on the floor [...] / see that he is a bigger child for the his age, but the grid was more or less height (gesture) and yet he fell. (I 2)

[...] when I arrived I found it strange that her grid was a little short. She's about to be two years old, so she can stand [...] (I 9)

Regarding the grid, someone was with him and did not lift the grid because she needed to get something. (1 51)

[...] he keeps hitting his face, he slips, he keeps his legs out of the cradle [...] They'll change him, put him in a crib that has a grid. She saw it now and realize that it's very dangerous. (E 13)

\section{Communication}

Another aspect that the interviewees mentioned was the communication between and with the professionals. For them, failed communication is perceived in the medication process, diet therapy, transfer of care, listening to complaints from relatives, and the absence of sensitive listening, lack of information on visiting hours, mismatched information 
between professionals, and prognostic communication and patient exams.

He did some tests and they didn't tell me that he had meningitis, so I got to know Monday, and he's been here since Wednesday [..] But I said, "How did I not know?". (I 10)

[...] until the professor who's the supervisor comes, there are three doctors, four doctors ... and then each one says something different, right [...] (| 49)

But this for me was their biggest mistake, saying that my son was not going to survive and that they had no medicine, no surgery, there was nothing [...] that we had to wait for his death [...] (I 55)

[...] as during the visit I also asked for a paper to know what the visit was like because nobody told me anything [...] (E 2)

She tried to tap him several times, my son was feeling sick during the night [...] And I was saying "lady, he only has a vein in his head" [...] By then I was tired of see her sticking him, and he has a calcium-leaking arm [...] she threatened to pierce his arm. That was the breaking point [...] (U 7)

What converges to the issue of communication between professionals and family members is the relationship developed by them during hospitalization. For many participants, the patient does not receive the necessary attention to their safety when the relative is not around, just as they do not feel welcomed and heard by the professionals.

It's a complaint about nursing techniques, they could be a little more considerate. The child gets agitated and they leave them last. The child cries, until sleep [...] (I 5)

[...] And then someone called V. was taking care of my son, but they told me she was throwing him this way and that way and said "shut up". The good thing is that I didn't see it, but another mother saw it and told me [...] (I 19)

[...] there are moments they stay for a long tim, e you know, outside the room [...] This week, there was one of the little babies that was in another bed, I had to get her because she was with ... they made like a nest for her, and she had her head in a way that she couldn't breathe. The nurse wasn't in the room, the other one was with other children, and I had to move the child. [...] (I 50)

\section{Patient Identification}

Patient identification, one of the most important strategies for patient safety, also showed flaws according to family members, due to the absence or lack of verification of the identification bracelet.

[...] since yesterday when she arrived until now they have not put a bracelet on her [...] they entered here now in the room and said she is a boy, but she is a girl. She has no name to identify her. (E 9)

Yes, he was downstairs, they didn't put the bracelet on, he came here without the bracelet on his arm [...] (I 16)

But now my child is without identification because they had to do a procedure and at the time they tore it and took it, but then did not bring another. The right thing would be for them to bring another, right. (I 33)

So ... everyone has to look at the bracelet right ... like, there are twins, you can differentiate each other right, but if it were two boys or two girls? Would you know what the medication is? If both are in the same crib [...] (| 45)

\section{Care processes / procedures}

Regarding care processes and procedures, incidents were identified in tube care, material disposal, delayed of referral for examinations and surgical procedures, excessive attempts at venous puncture, carelessness during catheter manipulation, early hospital discharge, risks related to the child's natural limitations to certain procedures, excessive people in the patient's space, delayed care in emergency situations, lack of professional attention to patient care and devices.

[...] Yesterday just before he came here I asked her to take his probe with pee and they waited for him to pee, he was supposed to wait 10 minutes. Does a child this size can wait 10 minutes? There is no way [...] (E3)

[...] what we notice is when, for example, a very large movement of people and sometimes, you waited a while for the child to come to breastfeed or to sleep, and then another person enters [...] so with this safety criterion, I believe that the argument I make is related to this [...] (E14)

It took too long, they had to transfer her and they took too long. Then I said "I want to see if she has a crisis there, I want to see who will hold her", "oh if we can we will deal with it". I arrived at 9 p.m. and was attended at 12 a.m. It took a long time. (E 7)

Today they should take him to the surgery to take out the infection and so far they did not call, his bandage was all wet and I was the one who changed it, the doctors did not 
come to see how he is, they gave him the antibiotic, but they also need to do the bandages and they are not doing it as they should. (E 11)

[...] the Omeprazol is an oral drug. And she didn't make sure it was oral and put it through the tube, and it wasn't well diluted, because it was set to be taken orally and so it ended up obstructing the tube. (1 57)

[...] But I went to complain about the delay of my son's surgery to the ombudsman and they said they could do nothing [...] ( 20)

[...] Even in the catheter manipulation, there is some that are not as careful as others right [...] (I 36)

[...] they are in a hurry, I think, to send the children away faster, right... without healing 100\%, right [...] (I 44)

\section{Access to the institution}

Family members also related patient safety incidents with weaknesses in identifying and selecting who enters the hospital to visit patients.

Sometimes, because there are people entering the emergency room, they can go to the child's hospital section and here they only go up if they warn us, but I've seen cases of parents, relatives entering up here without warning [...] (I 18)

[...] even the identification, it is terrible, anyone comes in, I saw people coming in who were not the father and mother and who shouldn't come [...] (I 51)

Patient safety incidents reported by relatives of hospitalized children are varied and cover different stages of the care processes.

\section{DISCUSSION}

Regarding drug therapy, a multicenter study conducted in the United States with patient safety surveillance reports showed that most adverse events reported by patient relatives involved temporary patient injury, which required intervention in $84.9 \%$ of cases or increased hospitalization time (15.2\%) of children; most incidents were directly related to medication ${ }^{(8)}$.

An integrative literature review on caregivers view on drug-related incidents identified that most of these errors were related to work overload and management issues.
Improved work conditions, continuing education, and safety culture were found to be the main preventive measures ${ }^{(9)}$.

Among the main strategies showed in literature to reduce the incidence of medication errors are improvements / implementation of electronic prescription systems, qualification of professionals working in pediatrics and improvements in communication regarding the safe administration of drugs among professionals that compose the team and of the team with the families ${ }^{(10)}$. This action converges with the findings of our study, pointing out that inefficient communication in drug therapy is an important factor identified by the family members of children, that can lead to incidents.

Hand and environment hygiene was the result of another study ${ }^{(11)}$, in which, corroborating the findings of this investigation, some companions observed that good practices for infection control are not always followed, which demonstrates the family members awareness about the need to protect the children from infection.

An intervention study identified increased adherence and positive perception of handwashing following the use of the Guide for the Implementation of the Multimodal Strategy from the WHO, to improving hand hygiene in Pediatric Intensive Care Units. The strategy included four-month adherence observations, dissemination of results, the implementation of a commemorative week, availability of educational material, and annual training ${ }^{(12)}$.

Hand hygiene and the use of PPE are also directly linked to measures cited by the authors to prevent healthcare-related infections. This study also shows that continuing education is an important instrument that promotes changes in practice, and that combined with the role of the Hospital Infection Control Commissions $(\mathrm{CClH})$, raises awareness among professionals ${ }^{(13)}$.

In a study similar to this one, the diet therapy of hospitalized children was also cited by family members as a concern for the patient's physical safety ${ }^{(11)}$. Correct verification of the patient's name, dosage, caution in the infusion of parenteral diets and greater flexibility to bring it closer to the diet therapy offered at home, can be actions indicated to reduce incidents and improve the quality of child assistance in this area.

The emphasis on caring for children reiterates the danger and gives visibility to the risk of falls, since due to the growing and developing conditions of children they are more predisposed to falls. Recommendations for actions to prevent falls include: maintaining one of the cribs grids up during change of clothes / diapers; ensure that children $>6$ 
months $\leq 36$ months are transported on a stretcher in the company of the responsible when undergoing anesthetic / sedation procedures or in a wheelchair on the parents lap; and assess the risk of falls at the time of child admission. Guidance to the child and family member about the risk of falls related to factors such as age, diagnosis, cognitive factors, past history, prolonged fasting, surgery / sedation / anesthesia, and / or medication, and how to prevent them is also indicated, and it is essential that professionals inform the family member whether the child is permitted or not to walk ${ }^{(12)}$.

The actions related to communication are complex and should be discussed within hospital institutions, because when they do not occur effectively, they pose a risk to patient safety and are related to multiple errors within the care context. Communication incidents are the main cause of failures that affect patient safety. Studies highlight in their results that, like the family members interviewed for this research, they recognized the link between communication and safety. Thus, actions are needed to improve communication between health professionals and family members and / or among the healthcare team members themselves, reflecting in greater safety for pediatric patients ${ }^{(14-15)}$.

Studies reiterate the importance of including family members in the care of hospitalized children, especially in the role of patient safety surveilling; thus reducing the number of errors through the safety incident reports made by family members. A 16\% increase in overall medical error detection and a $10 \%$ increase in adverse event reporting were identified in reports from relatives, which was more efficient than the ones made by professionals. This shows the importance of including family members in safety surveillance in the care of hospitalized pediatric patients(15-18).

However, as family members are not only concerned with issues directly related to patient safety, their reports can be very useful for increasing the quality of care for hospitalized children, broadening the view of health professionals. But for parents to be effective partners in the prevention of errors, they need to be well informed about care plans, always updated on changes in the therapy adopted and encouraged to participate and manifest themselves ${ }^{(15)}$.

Still regarding the communication between professionals and relatives, patient relatives demonstrate the need for the nursing staff to reevaluate and reflect on their role in providing information and guidance to patients and caregivers. Also, family members recognize the need for greater humanization in care since nurses have the potential to make hospitalization less traumatic for children specially through communication ${ }^{(16)}$.

The family members in this study also reported incidents related to patient identification. The absence of identification bracelets or lack of verification demonstrate shortcomings in the care process, corroborating a study carried out in PICU, which showed that identification information fixed at the head of the bed or in the box door was the most used resource for patient identification, which can expose children to risks since this form of identification usually does not accompany the patient in transportation to perform diagnostic or therapeutic procedures outside the unit of origin ${ }^{(17)}$.

The literature confirms the importance of ensuring the correct identification of the patient for their safety. During care, there are numerous situations that interfere with patient identification and should be considered, such as the presence of patients with the same or similar names. As a strategy indicated to ensure patient safety, it is suggested to always check the full name of the patient and not to use only other indicators such as bed number. Correct patient identification is also related to ensuring the correct administration of drugs and all other patient care. In addition, patient identification can be considered as a guarantee of their rights, thus ensuring that patients will receive care planned and directed to their needs, without circumstances that cause harm and affect their safety ${ }^{(18)}$.

Attention to patient identification is not only important for the patient, but also for the safety of the professionals, since everyone involved in the care process suffers from the implications of a patient safety incident. Therefore, updating professional knowledge is extremely valuable for their protection and for patient safety, especially for professionals working in sectors that have particularities, such as pediatrics, which requires specific actions aimed at this public ${ }^{(19)}$.

Shortcomings regarding the control of access of people visiting hospitalized children was also mentioned by family members as an incident. This perspective, although more recent, was also reported as a concern for patient safety in a research conducted in a neonatal unit, in which patients placed significant importance on the availability of a full-time professionals in the reception of the service, so the flow of people can be monitored ${ }^{(20)}$. Thus, the control of the flow of people in health services is a new dimension to be considered for patient safety and needs further investigation. 


\section{口INAL CONSIDERATIONS}

The results of the study indicated incidents related to drug therapy, hand and environment hygiene, patient identification, risk of falls, diet therapy, access to the service, communication and relationship of professionals with family members, and care processes and procedures. Despite the various situations identified as safety incidents and risk factors by the participants, both are extremely important for the understanding of the concept that family members have about patient safety, it was found that their knowledge on the subject has limitations that should be addressed by health institutions.

The main incidents reported by participants showed that in order to reverse the situation aiming at a safer care for hospitalized children and adolescents, it is crucial that professionals and managers stay aware of the size and complexity of the problem, encouraging family participation in care and in incident prevention.

The inclusion of family members in all care processes enables them to identify possible risks and incidents in the care of hospitalized children. The insertion of the family means having an open and effective communication, with dialogue that enables the family member to question therapeutic behaviors and participate in decision making in tandem with the multiprofessional team.

Informing the patient and family member about the processes during care and the importance of certain procedures contributes to the promotion of a safety culture. Thus, this study contributes for strategies to be reconsidered with regards to the inclusion of these relatives in patient safety issues during children hospitalization. In addition, it collaborates by furthering the scientific knowledge on the subject, enabling the awareness of nurses in training and encouraging new researches aiming at the qualification of care.

The limitations of this study are related to the participants' difficulty in reporting experienced situations, their lack of knowledge about the theme and the apprehension of moving away from the children's beds. New studies are suggested to test the use of incident reporting form for families to report incidents during the child hospitalization.

\section{Q REFERENCES}

1. World Health Organization $(\mathrm{CH})$. Conceptual Framework for the International Classification for Patient Safety: version 1.1: final technical report January 2009. Genebra: WH0; 2009 [cited 2009 Apr 10]. Available from: https://www.who. int/patientsafety/taxonomy/icps_full_report.pdf
2. Maia CS, Freitas DRC, Gallo LG, Araújo WN. Registry of adverse events related to health care that results in deaths in Brazil, 2014-2016. Epidemiol Serv Saúde. 2018;27(2):e2017320. doi: https://doi.org/10.5123/S167949742018000200004

3. Souza JF, Vituri DW. Notificações de incidentes relacionados à segurança do paciente como ferramenta de gestão para a mudança da cultura organizacional. Rev Eletron Acervo Saúde. 2019;17 Supl:e237. doi: https://doi.org/10.25248/ reas.e237.2019

4. Antão C, Rodrigues N, Sousa F, Anes E, Pereira A. Hospitalização da criança: sentimentos e opiniões dos pais. INFAD Rev Psicol. 2018 [cited 2019 apr 10];1(1):125-32. Available from: http://www.infad.eu/RevistalNFAD/0JS/ index.php/JODAEP/article/view/1201/1044

5. Peres MA, Wegner W, Cantarelli-Kantorski KJ, Gerhardt LM, Magahães AMM. Perception of family members and caregivers regarding patient safety in pediatric inpatient units. Rev Gaúcha Enferm. 2018;39:e2017-0195. doi: https://doi.org/10.1590/1983-1447.2018.2017-0195

6. Hoffman JM, Keeling NJ, Forrest CB, Tubbs-Cooley HL, Moore E, Oehler $E$, et al. Priorities for pediatric patient safety rResearch. Pediatrics. 2019;143(2):e20180496. doi: https://doi.org/10.1542/peds.2018-0496

7. Minayo MCS. 0 desafio do conhecimento: pesquisa qualitativa em saúde. 14. ed. São Paulo: HUCITEC; 2014.

8. Khan A, Coffey M, Litterer KP, Baird JD, Furtak SL, Garcia BM, et al. Families as partners in hospital error and adverse event surveillance. JAMA Pediatr. 2017;171(4):372-81. doi: https://doi.org/10.1001/jamapediatrics.2016.4812

9. Forte ECN, Pires DEP, Padilha MI, Martins MMFPS. Nursing errors: a study of the current literature. Texto Contexto-Enferm. 2017;26(2):e01400016. doi: https:// doi.org/10.1590/0104-07072017001400016

10. Basco WTJ, Gamer SS, Ebeling M, Freeland KD, Hulsey TC, Simpson K. Evaluating the potential severity of look-alike, sound-alike drug substitution errors in children. Acad Pediatr. 2016;16(2):183-91. doi: https://doi.org/10.1016/j. acap. 2015.06.014

11. Lyndon A, Jacobson CH, Fagan KM, Wisner K, Franck LS. Parents' perspectives on safety in neonatal intensive care: a mixed-methods study. BMJ Qual Saf. 2014;23(11):902-9. doi: https://doi.org/10.1136/bmjgs-2014-003009

12. Gurgel SS, Ferreira MKM, Sandoval LS, Araújo PR, Galvão MTG, Lima FET. Nursing competencies in the prevention of falls in children in light of the Galway consensus. Texto Contexto Enferm. 2017;26(4):e03130016. doi: https://doi. org/10.1590/0104-070720170003140016

13. Monteiro TS. Infecção hospitalar: visão dos profissionais da equipe de enfermagem. Rev Epidemiol Control Infec. 2015;5(2):84-8. doi: https://doi. org/10.17058/reci.v5i2.5665

14. Vanderbilt AA, Pappada SM, Stein H, Harper D, Papadimos TJ. Increasing patient safety with neonates via handoff communication during delivery: a call for interprofessional health care team training across GME and CME. Adv Med Educ Pract. 2017;8:365-7. doi: https://doi.org/10.2147/AMEP.S129674

15. Khan A, Furtak SL, Melvin P, Rogers JE, Schuster MA, Landrigan CP. Parent-reported errors and adverse events in hospitalized children. JAMA Pediatr. 2016;170(4):e154608. doi: https://doi.org/10.1001/ jamapediatrics.2015.4608

16. Carvalho JL, Silva AEBC, Sousa MRG, Freitas IS, Bezerra ALQ. Assessment of quality and safety of nursing assistance to the hospitalized child: Perception of accompanying. J Nurs UFPE on line. 2017;11(Supl 11):4700-8. 
17. Bernal SCZ, Raimondi DC, Oliveira JLC, Inoe KC, Matsuda LM. Patientidentification practices in a pediatric intensive care unit. Cogitare Enferm. 2018;(23)3:e55390. doi: https://doi.org/10.5380/ce.v23i3.53390

18. Souza S, Tomazoni A, Rocha PK, Cabral PFA, Souza AIJ. Identificação da criança na pediatria: percepções dos profissionais de enfermagem. Rev Baiana Enferm. 2015;29(1):5-11.
19. Silva HS, Araújo TS, Alves AS, Silva MN, Costa HOG, Melo M, et al. Errorproducing conditions in nursing staff work. Rev Bras Enferm 2018;71(4):185864. doi: https://doi.org/10.1590/0034-7167-2017-0192

20. Rodrigues FA, Wegner W, Kantorski KJC, Pedro ENR. Patient safety in a neonatal unit: concerns and strategies experienced by parents. Cogitare Enferm. 2018; (23)2. doi: https://doi.org/10.5380/ce.v23i1.52166

\section{- Corresponding author:}

Letícia Maria Hoffmann

E-mail: leticiamhoffmann8@gmail.com

\section{Associate editors:}

